\title{
EDITORIAL DO VOLUME 4, NÚMERO 1 (2015) DA REVISTA INOVA SAÚDE
}

Nesta nova edição da revista Inova Saúde, são apresentadas com propriedade diversas temáticas, dando continuidade a este trabalho de divulgação científica da Unidade Acadêmica de Ciências da Saúde da UNESC e atestando o crescimento qualitativo deste periódico.

Autores de diversas universidades nacionais contribuem nesta edição com artigos detectando de forma renovada e pontual a necessidade da Educação Permanente focada nos profissionais da saúde atuantes na Atenção Básica. São também identificadas e abordadas as concepções teórico-filosóficas que permeiam o ideário de coordenadores da Atenção Básica sobre processos de Educação Permanente em Saúde, chamando a atenção para o fato de que a consolidação da Educação Permanente como operadora de mudanças nas práticas, implica em maior compreensão e envolvimento dos próprios coordenadores.

No processo de trabalho da Estratégia Saúde da Família, são evidenciadas, em outro artigo, as dificuldades dos Agentes Comunitários de Saúde frente ao enfrentamento e superação de desafios postos em sua micro área. Além disso esse número apresenta a atual problemática relativa a prescrição de fitoterápicos fornecidos pelo Sistema Único de Saúde. Por meio de revisão crítica da literatura, busca-se contribuir para a análise das possíveis interações dos fitoterápicos com a medicação alopática. $\mathrm{Na}$ assertiva dos autores, o tema é trazido com o propósito de fortalecer o conhecimento de profissionais da área e saúde tanto sobre os efeitos medicinais quanto tóxicos das plantas, concorrendo, portanto, para adequada implementação das próprias práticas de fitoterapia no Sistema Único de Saúde.

Outras duas abordagens são feitas considerando a dimensão psicossocial na Atenção à Saúde. Por meio de revisão da literatura, um dos artigos enfoca a relação do estresse como fator associado ao Diabetes Mellitus tipo 2. Os autores chamam a atenção para a necessidade de medidas que incluam a detecção e o controle de estresse com vistas a melhorar os níveis glicêmicos, prevenir o aparecimento de complicações e melhorar a qualidade de vida de indivíduos acometidos. Outra interessante abordagem de um tema que, igualmente, impacta diretamente 
na qualidade de vida, avalia o comportamento imitativo de adolescentes e sua influência sobre o uso de substâncias, chegando à conclusão de que este é um dos fatores que podem levar à adoção de comportamento de uso de drogas.

Finalmente, mas não menos importante, em seção ligada à Saúde Funcional, é traçado o perfil das demandas para reabilitação pelo Sistema Único de Saúde em serviços credenciados em Criciúma, SC, salientando-se os acometimentos ortopédicos, neurológicos e traumatológicos. Os autores contemporizam ainda, a necessidade de articulação em rede com as políticas públicas de prevenção e promoção da saúde do usuário.

Como é possível verificar, as contribuições dos autores constituem uma variedade de reflexões preponderantemente sobre práticas ligadas ao nosso Sistema Único de Saúde, o que é constatado por nós, do corpo editorial, com renovada satisfação, tendo em vista o amplo engajamento da nossa Unidade Acadêmica de Ciências da Saúde nessas questões, em especial o recente Mestrado em Saúde Coletiva da UNESC em suas linhas de pesquisa: Educação e Gestão do Trabalho na Saúde,
Epidemiologia aplicada em Serviços de Saúde, e Promoção da Saúde e Integralidade.

Convido-os a ler as diversas abordagens, sob a ótica do compartilhamento de ideias, esperando que esse diálogo com os autores seja profícuo. A construção desta edição, sem dúvida, é resultado do esforço inequívoco de seu corpo editorial, mas sobretudo da contribuição dos diversos autores. A eles, os autores, preponderantemente, 0 nosso agradecimento!

\section{Profa Dra Ingrid Dalira Schweigert} Perry

Editora de Seção - Inova Saúde Professora do Programa de PósGraduação em Saúde Coletiva (PPGSCol) 